\title{
Influence of dry and wet atmospheres on the unsteady thermal behaviour of materials in a cavity
}

\author{
Jean-Yves Noël, Guillaume Polidori, Jacques Padet \\ Laboratoire de Thermomécanique, Faculté des Sciences, BP 1039, 51687 Reims, France \\ Elmar Junker \\ Electrolux Hot Tech-Centre, Sjaellandsgade 2, 7000 Fredericia, Denmark \\ Presented at the 14th European Conference on Thermophysical Properties, Lyon, France, \\ $16-19$ September 1996
}

\begin{abstract}
An experimental study has been made of the influence of different convective atmospheres on the thermal behaviour of materials in a rectangular cavity. The atmospheres can be dry air, humid air, or superheated steam. Two kinds of materials are studied: porous and nonporous. The comparisons show a benefit in using humid atmospheres to reach the saturation temperature in a minimum of time. Afterwards the behaviours tend to those obtained with dry air. The presence of humidity within the material modifies the heating kinetics as well under dry air as under steam. By normalising the central temperature, predictive models have been proposed, giving the central temperature history for each material under the different kinds of convective atmospheres.
\end{abstract}

\section{Introduction}

The aim of this work is to obtain precise details on the influence of dry and humid atmospheres on the temperature evolution of samples in a given heated cavity. For more complementary information, the thermal consequences of using as samples either porous or water-repellent materials have also been estimated. We present the experimental study of heating a Hipor brick as porous material, and a Duralumin brick under the influence of convective dry air $\left(100,150,200{ }^{\circ} \mathrm{C}\right)$ and wet or superheated steam $\left(100,150,200^{\circ} \mathrm{C}\right)$. The Hipor brick can be initially dry or water saturated.

From the data, predictive heating models have been established, the purpose being to simulate the thermal behaviour of those materials whatever the desired final temperature in the cavity. According to the complexity of the thermal features, the analyses have been made either under dimensional or dimensionless forms.

\section{Experimental conditions}

Experiments have been carried out in a parallelepiped-shaped oven equipped with a fan which permits the generation of the different convective atmospheres up to a limit of $240^{\circ} \mathrm{C}$. Three materials were considered, namely a piece of Duralumin $(200 \times 120 \times 50$ $\left.\mathrm{mm}^{3}\right)$, and dry and initially water-saturated Hipor bricks $\left(250 \times 120 \times 50 \mathrm{~mm}^{3}\right)$, the volumic porosity of which was about $78 \%$. The central temperature of each material was followed by means of a type $\mathrm{K}$ thermoelement positioned exactly at the geometric centre of the material. The samples were initially at room temperature, $20 \pm 2{ }^{\circ} \mathrm{C}$. The brick was water saturated by placing it for about $12 \mathrm{~h}$ in a water pot at room temperature. The tests were always started in the cavity under the required atmospheric conditions, until the material temperature reached the external flow temperature.

\section{Results and analysis}

First, we present the experimental temperature features, then predictive models are proposed for the different cases. 
3.1 Experimental results

The different experimental results are shown in figure 1.

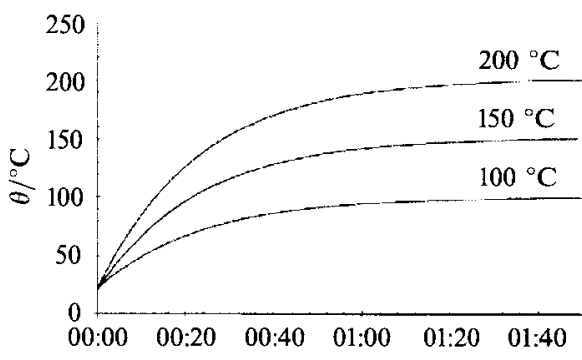

(a)

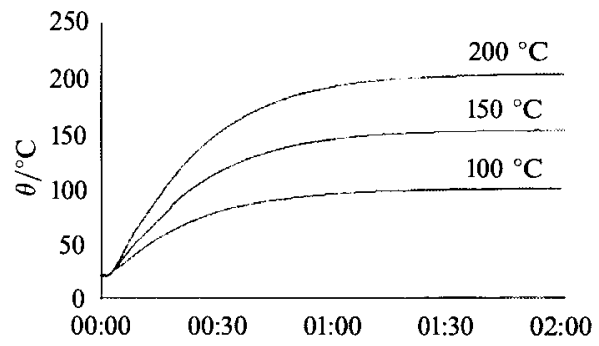

(c)

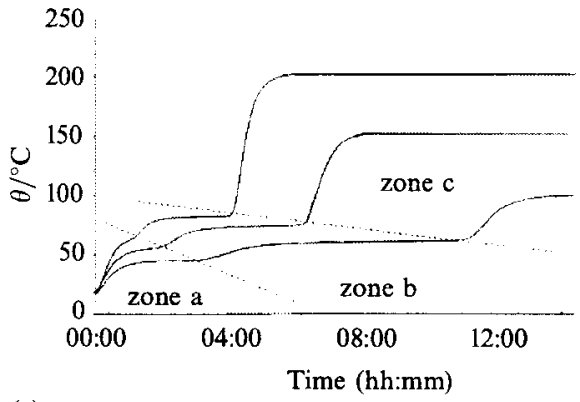

(e)

Figure 1. Experimental results for the central temperature behaviour inside (a) and (b) Duralumin, (c) and (d) dry brick, and (e) and (f) wet brick for dry air (left) and steam (right). In (f), 1 corresponds to steam at $100{ }^{\circ} \mathrm{C}$, and 2 to steam above $100{ }^{\circ} \mathrm{C}$.

3.1.1 Duralumin. In dry air, the central temperature of Duralumin increases monotonically and tends asymptotically to the flow temperature. In steam over $100{ }^{\circ} \mathrm{C}$, the temperature behaviour is different. There is first a fast increase of the temperature until the saturation temperature is reached. Then, there is a slowing down of the temperature rise, which becomes approximately linear. The inclination and the length depend on the external temperature. Finally, there is a third step, where the temperature increases faster and asymptotically to the external temperature.

The wet steam gives a fast increase of temperature until $100^{\circ} \mathrm{C}$, which is then maintained. A condensation film is formed on the upper surface during the phase of temperature rise. This film continues to exist while the temperature remains at $100{ }^{\circ} \mathrm{C}$.

The behaviour under dry steam is also related to the presence of a condensing film, chiefly on the upper surface of the sample. Indeed, during the first phase, the Duralumin temperature is below $100{ }^{\circ} \mathrm{C}$ : there is a condensation film which appears mainly on the upper surface, releasing large quantities of heat. Consequently, the temperature increases 
very fast. In the second phase (the material temperature has reached $100{ }^{\circ} \mathrm{C}$ ), there is no more condensation: the condensation film is subjected to both radiation (Noël 1996; Noël et al 1996) and convection, as are the other faces. The internal temperature increases and the condensation film is evaporated more or less quickly, depending on the flow temperature. When the film has completely disappeared, the third step starts with an asymptotic increase of the temperature toward that of the cavity.

3.1.2 Initially dry brick. Similar behaviour to that previously mentioned is observed in the case of a dry brick for both dry air and steam. However, differences exist. First, we noted the presence of an initial delay of time, due to the insulating properties of the dry brick, compared to Duralumin. Second, we noted that the final temperature of the first phase was not $100{ }^{\circ} \mathrm{C}$ but rather around $90{ }^{\circ} \mathrm{C}$, when the steam temperature is above the saturation temperature. This point is not easily explained. However, we can assess that the temperature of the outer part of the brick reaches $100{ }^{\circ} \mathrm{C}$ earlier than the centre. So, as the absorbed water is present on the outer part of the brick, the energy provided is no longer used to heat the brick by conduction but rather to evaporate the absorbed water. Consequently, the central temperature rise slows down.

Only wet steam shows no different temperature behaviour between Duralumin and dry brick.

3.1.3 Initially wet brick. With the initially water-saturated brick, we observed a more complex thermal behaviour than for the others for dry air and steam. For dry air, the temperature evolution was clearly divided into three successive steps, each including an increase of the temperature up to a plateau. The arrangement of the curves shows a gradation function of the flow temperature. We noted that the first and second plateaux have temperatures lower than $100^{\circ} \mathrm{C}$. For steam, we must consider once more two cases. The first case corresponds to wet steam where the central temperature increases very fast up to $100{ }^{\circ} \mathrm{C}$ and is then maintained at this value all through the test. Only condensation occurs, as it corresponds to the saturation conditions. The second case concerns the use of dry steam: the central temperature behaviour is not easy to distinguish. However, we have noted that the temperature increases up to a first plateau and, depending on the flow temperature, it increases more or less quickly to a second plateau, which remains close to the first one. In the third step the central temperature approaches the flow temperature.

It was noticed that the brick was fully dry when the final temperature was reached. Moreover, it can be shown that the time to reach the steady state decreases as the atmospheric temperature increases.

The heating process of the initially saturated brick corresponds to drying. The mechanisms of the drying by dry air and steam are well described by Moyne (1985). The only difference between dry air and steam is that the drying process starts immediately for dry air, but only after a condensing phase for steam.

\subsection{Predictive models}

As the previous analysis on each sample shows, the central temperature is mainly influenced by the external flow temperature, $\theta_{\mathrm{r}}$. This will be the main parameter in the following predictive model giving the central temperature under different conditions. We have used simple mathematical laws to model the different phases: an exponential law in the form

$$
\frac{\theta-\theta_{1}}{\theta_{2}-\theta_{1}}=1-\exp \left(-\frac{t-t_{\mathrm{r}}}{\tau}\right)
$$


and a linear law in the form

$$
\frac{\theta-\theta_{1}}{\theta_{2}-\theta_{1}}=C_{\mathrm{D}} t+D_{0},
$$

where $t_{\mathrm{r}}$ is a time delay and $\tau$ a time constant. $\theta_{1}$ and $\theta_{2}$ are respectively the starting and ending temperatures of the phase, $C_{\mathrm{D}}$ is the slope coefficient, and $D_{0}$ the ordinate at the origin. The time constant is the time needed to reach $63 \%$ of the temperature variation.

The parameters $\tau, t_{\mathrm{r}}, \theta_{1}, \theta_{2}, C_{\mathrm{D}}$, and $D_{0}$ are expressed to a first approximation as linear functions of the flow temperature, $\theta_{\mathrm{f}}$. The parameters are given in different tables corresponding to the three cases considered (see below).

In order to test the mathematical approach, additive tests at 120,175 , and $240{ }^{\circ} \mathrm{C}$ have been carried out.

3.2.1 Duralumin. The normalised temperatures, defined as $\theta^{*}=\left(\theta-\theta_{\mathrm{i}}\right) /\left(\theta_{\mathrm{f}}-\theta_{\mathrm{i}}\right)$, where $\theta_{i}$ is the initial temperature and $\theta_{\mathrm{f}}$ is the flow temperature, obtained at the geometric centre of the Duralumin, are presented in figure 2 . The presence of any time delay was neglected. The normalised curves for dry air are characterised by a unique curve. This curve (2) is modelled by an exponential law, as for humid steam (I).

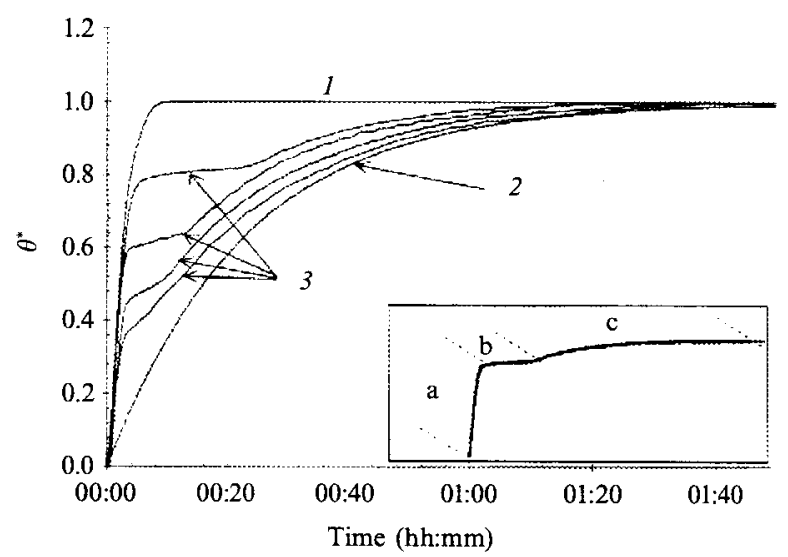

Figure 2. Normalised central temperature for Duralumin: 1 , steam at $100{ }^{\circ} \mathrm{C} ; 2$, dry air; 3 , steam above $100{ }^{\circ} \mathrm{C}$.

The curves for superheated steam (3) present three consecutive phases (a, b, c). The curves noted (a) and (c) are modelled as exponential laws, whereas (b) is modelled as a linear law. It is important to note that the final times of the first and second phases are variable and are also expressed as linear functions of the flow temperature.

We noted the extreme behaviours of humid steam and the dry air law. The curves for superheated steams are always located between the two extremes. The parameters for each curve or group of curves are given in table 1.

3.2.2 Initially dry brick. The normalised temperatures obtained with the dry brick are presented in figure 3. The same notations are used as for Duralumin. The similarities with the model of Duralumin are many, with the following exceptions: a time delay must now be taken into account, which seems to be independent of the atmospheric nature and its temperature; for dry steam, the two discontinuities respectively at the end of the first and second phases seem to be independent of the flow temperature. The first is encountered after $10 \mathrm{~min}$ and the second appears after $14 \mathrm{~min}$. The resulting parameters are given in table 1. 
Table 1. Parameters satisfying the set of equations giving the central temperature of Duralumin and initially dry brick for dry air or steam (from 100 to $240{ }^{\circ} \mathrm{C}$ at atmospheric pressure).

\begin{tabular}{llcl}
$\begin{array}{l}\text { Designation } \\
\text { of curve }\end{array}$ & Parameter & Duralumin & Initially dry brick \\
\hline 1 & $t_{\mathrm{r}} / \min$ & 0 & 3.7 \\
& $\tau / \min$ & 2.3 & 1.1 \\
2 & $t_{\mathrm{r}} / \min$ & 0 & 3.7 \\
& $\tau / \min$ & 23 & 21.8 \\
$3(\mathrm{a})$ & $t_{\mathrm{r}} / \min$ & 0 & 3.7 \\
& $\tau / \min$ & $-8.7 \times 10^{-3}\left(\theta_{\mathrm{f}} /{ }^{\circ} \mathrm{C}\right)+3.2$ & $1.1 \times 10^{-2}\left(\theta_{\mathrm{f}} /{ }^{\circ} \mathrm{C}\right)+1.83$ \\
$3(\mathrm{~b})$ & $t_{\mathrm{f} 1} / \min$ & $-14.47 \times 10^{-2}\left(\theta_{\mathrm{f}} /{ }^{\circ} \mathrm{C}\right)+4.2$ & 10 \\
& $C_{\mathrm{D}}$ & $1.28 \times 10^{-4}\left(\theta_{\mathrm{f}} /{ }^{\circ} \mathrm{C}\right)-1.4 \times 10^{-2}$ & $2.5 \times 10^{-5}\left(\theta_{\mathrm{f}} /{ }^{\circ} \mathrm{C}\right)-7.8 \times 10^{-4}$ \\
$3(\mathrm{c})$ & $D_{0}$ & $-4.1 \times 10^{-3}\left(\theta_{\mathrm{f}} /{ }^{\circ} \mathrm{C}\right)+1.24$ & $-3.5 \times 10^{-3}\left(\theta_{\mathrm{f}} /{ }^{\circ} \mathrm{C}\right)+1.06$ \\
& $t_{\mathrm{f} 2} / \min$ & $-8.4 \times 10^{-2}\left(\theta_{\mathrm{f}} /{ }^{\circ} \mathrm{C}\right)+26.2$ & 14 \\
& $t_{\mathrm{r}} / \min$ & $0.11\left(\theta_{\mathrm{f}} /{ }^{\circ} \mathrm{C}\right)-28.5$ & $0.08\left(\theta_{\mathrm{f}} /{ }^{\circ} \mathrm{C}\right)-12.7$ \\
& $\tau / \min$ & 23 & 21.8
\end{tabular}

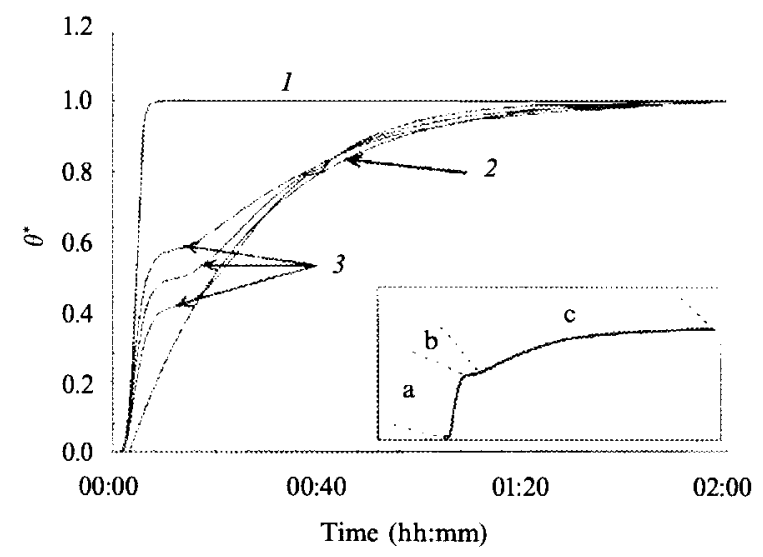

Figure 3. Normalised central temperature for dry brick; 1,2 , and 3 as in figure 2.

3.2.3 Initially saturated brick. As the time taken to obtain the steady state varies with the temperature and the nature of the atmospheres, the curves for dry air and steam cannot be combined and normalised. The curves are located on figure 1 and the modelling parameters are given in table 2 . The three phases described in the analysis are respectively designated by $a, b$, and $c$. The first phase is approached by an exponential law with a time delay, $t_{\mathrm{r}}$, and a time constant, $\tau_{1}$. The second and third phases are

Table 2. Parameters satisfying the set of equations giving the central temperature of initially water-saturated brick for dry air or superheated steam (from 100 to $240^{\circ} \mathrm{C}$ at atmospheric pressure).

\begin{tabular}{lll}
\hline Parameter & Dry air & Superheated steam \\
\hline$t_{\mathrm{r}} / \min$ & 7 & 9.8 \\
$t_{\mathrm{f} 1} / \mathrm{min}$ & $-0.83\left(\theta_{\mathrm{f}} /{ }^{\circ} \mathrm{C}\right)+258$ & $-2\left(\theta_{\mathrm{f}} /{ }^{\circ} \mathrm{C}\right)+462$ \\
$t_{\mathrm{f} 2} / \mathrm{min}$ & $-2.96\left(\theta_{\mathrm{f}} /{ }^{\circ} \mathrm{C}\right)+872$ & $-3.3\left(\theta_{\mathrm{f}} /{ }^{\circ} \mathrm{C}\right)+939$ \\
$\theta_{1} /{ }^{\circ} \mathrm{C}$ & $0.13\left(\theta_{\mathrm{f}} /{ }^{\circ} \mathrm{C}\right)+36.1$ & $0.09\left(\theta_{\mathrm{f}} /{ }^{\circ} \mathrm{C}\right)+68.8$ \\
$\theta_{2} /{ }^{\circ} \mathrm{C}$ & $0.16\left(\theta_{\mathrm{f}} /{ }^{\circ} \mathrm{C}\right)+49.6$ & $0.14\left(\theta_{\mathrm{f}} /{ }^{\circ} \mathrm{C}\right)+67.6$ \\
$\tau_{1} / \min$ & $-0.125\left(\theta_{\mathrm{f}} /{ }^{\circ} \mathrm{C}\right)+45.8$ & $-0.06\left(\theta_{\mathrm{f}} /{ }^{\circ} \mathrm{C}\right)+24.4$ \\
$\tau_{2} / \min$ & $-0.555\left(\theta_{\mathrm{f}} /{ }^{\circ} \mathrm{C}\right)+156.4$ & $-0.281\left(\theta_{\mathrm{f}} /{ }^{\circ} \mathrm{C}\right)+115.5$ \\
$\tau_{3} / \min$ & $-0.19\left(\theta_{\mathrm{f}} /{ }^{\circ} \mathrm{C}\right)+68$ & $-0.294\left(\theta_{\mathrm{f}} /{ }^{\circ} \mathrm{C}\right)+91.9$ \\
\hline
\end{tabular}


modelled by exponential laws without time delay. The time constants are respectively $\tau_{2}$ and $\tau_{3}$. The end times $\left(t_{11}, t_{r_{2}}\right)$ and end temperatures $\left(\theta_{1}, \theta_{2}\right)$ of the two first phases change with the flow temperature. To a first approximation, they are modelled as linear functions of the flow temperature.

The curve for wet steam $(I)$ is entirely modelled as an exponential law. The main difference between the curves for dry air and steam on the water-saturated brick is observed only at $100^{\circ} \mathrm{C}$. This temperature is reached very soon for steam but very late for dry air.

\section{Conclusions}

Under dry air, the initially dry Hipor brick adopts the thermal behaviour of a homogeneous material such as the Duralumin. When the brick is initially water saturated, the heating kinetics are influenced by water transport within the material.

Under humid atmospheres, an initial phase of condensation on the material surface favours heating up to the saturation temperature. Beyond, the behaviours are the same as those obtained for dry air, for the Duralumin and the Hipor brick.

We have shown that it is possible to predict the temperature history of three different kinds of material in the range $100-240{ }^{\circ} \mathrm{C}$ at atmospheric pressure for convective dry air or steam in a parallelepiped-shaped cavity. Indeed, from the deduced experimental thermograms, we have proposed simplified mathematical simulations which are only dependent on the final required temperature, $\theta_{\mathrm{r}}$. The results are only suitable for a given type of cavity, such as convective household ovens. As the fan speed does not vary in a wide range from one oven to another, we estimate that the different relationships are usable for this type of cavity.

\section{References}

Moyne C, 1985, in Transferts en milieux poreux volume 1 (Carcans-Maubuissons, France: Groupement Universitaire de Thermique)

Noël J Y, 1996 Convection forcée d'air humide dans une enceinte de cuisson. Application à la cuisson d'aliments Thèse de doctorat, Université de Reims, France

Noël J Y, Polidori G, Padet J, 1996, in Proceedings, Congrès de la Societé Française des Thermiciues, Valenciennes volume 4 (Paris: Elsevier) pp 386-399 